\title{
FUNCTIONAL OUTCOME AFTER THE FONTAN OPERATION: FACTORS INFLUENCING LATE MORBIDITY
}

Thomas L. Gentles, FRACPa*

Kimberlee Gauvreau, $\mathrm{ScD}^{\mathrm{a}}$

John E. Mayer, Jr., MD

Steven B. Fishberger, MD ${ }^{a * *}$

Janice Burnett ${ }^{\text {a }}$

Steven D. Colan, $\mathrm{MD}^{\mathrm{a}}$

Jane W. Newburger, MD, MPH

Gil Wernovsky, MD****

\begin{abstract}
Objectives: The purpose of this study was to describe the functional outcome of a large number of patients after modifications of the Fontan operation and to investigate perioperative risk factors that might influence late functional state. Methods: A comprehensive cross-sectional review of the first 500 patients undergoing a Fontan operation at our institution was undertaken. Those surviving with an intact Fontan circulation were reviewed by questionnaire to assess functional status and medication history. Medical records, chest roentgenograms, echocardiograms, cardiac catheterizations, and laboratory investigations were also reviewed to assess postoperative status. Results: Three hundred sixty-three long-term survivors with an intact Fontan circulation were identified during crosssectional follow-up. Median age at operation was 5.0 years (range 0.4 to 31 years), and median follow-up was 5.4 years (range 1.7 to 20 years). Most patients $(91.1 \%)$ were in New York Heart Association class I or II. In a multivariate model, poor (class III or IV) functional state was associated with longer duration of follow-up $(p<\mathbf{0 . 0 0 1})$, a prior atrial septectomy $(p=$ $0.03)$, and a prior main pulmonary artery-ascending aorta anastomosis $(p=0.05)$. Conclusions: A poor functional outcome is uncommon after the Fontan operation but becomes more frequent with increasing duration of follow-up. (J Thorac Cardiovasc Surg 1997;114:392-403)
\end{abstract}

0 ver the past 20 years the early operative outcome after the Fontan operation has improved markedly. ${ }^{1-5}$ As more patients survive the operation, attention is being drawn to the late sequelae of the Fontan circulation. Recent reports have emphasized a continuing risk of late failure ${ }^{5-7}$ and a poor functional outcome in some long-term survivors. ${ }^{6,7}$

From the Departments of Cardiology ${ }^{\mathrm{a}}$ and Cardiac Surgery, Children's Hospital, Boston, and the Departments of Paediatrics and Surgery, Harvard Medical School, Boston, Mass.

K.G. was supported in part by the Kobren Fund.

Received for publication Nov. 5, 1996; revisions requested Jan. 22, 1997; revisions received June 2, 1997; accepted for publication June 2, 1997.

Address for reprints: Jane Newburger, MD, Department of Cardiology, Children's Hospital, 300 Longwood Ave., Boston, MA 02115.

*Current address: Department of Cardiology, Green Lane Hospital, Auckland, New Zealand.

**Current address: Division of Pediatric Cardiology, Mount Sinai Hospital, New York, N.Y

${ }^{* * *}$ Current address: Division of Pediatric Cardiology, Children's Hospital of Philadelphia, Philadelphia, $\mathrm{Pa}$.

Copyright (C) 1997 by Mosby-Year Book, Inc.

$0022-5223 / 97 \$ 5.00+0 \quad \mathbf{1 2 / 1 / 8 3 6 2 1}$
Exercise capacity is reduced, ${ }^{8}$ atrial arrhythmias are common, ${ }^{9,}{ }^{10}$ some patients may have neurologic or cognitive deficits, ${ }^{11}$ and protein-losing enteropathy can be debilitating. ${ }^{12}$ Increasing numbers of these patients with poor functional outcome are being referred for cardiac transplantation. ${ }^{5}$

The purpose of this study was to describe the functional outcome of a large number of patients after various modifications of the Fontan operation and to assess perioperative risk factors affecting outcome in this patient population.

\section{Methods}

Subjects. The first 500 patients who underwent various modifications of the Fontan procedure at Children's Hospital, Boston, were identified. The date of the operation ranged from April 1973 to July 1991, and cross-sectional follow-up of survivors was undertaken between September 1992 and July 1994. Patients who had died or had undergone cardiac transplantation or takedown of their Fontan circulation to a bidirectional cavopulmonary shunt or an aortopulmonary shunt before the cross-sectional study period were excluded from this analysis. An analysis of patient- and procedure-related risk factors influencing early and late failure is the subject of a separate report. ${ }^{5}$

Patient contact. Records of the Departments of Cardiology and Cardiac Surgery of Children's Hospital, Boston, 
were reviewed and referring centers were contacted. Each patient's current status (alive with a Fontan circulation or otherwise) was thus verified and his or her most recent known address obtained. A questionnaire addressing medication use, medical history, functional state, employment, and insurance status was sent to each surviving patient. If the questionnaire was not returned within 30 days, a second questionnaire was sent, and if this was not returned attempts were made to contact the patient by telephone. If the patient could not be contacted by these means, attempts were made to verify the address and, when necessary, the process was repeated. The study was approved by our institutional review board on August 18, 1992.

Perioperative variables. Medical records, preoperative echocardiographic and cardiac catheterization data, and operation notes were reviewed to obtain the perioperative data outlined in Appendix A.

Outcome measurements. The following outcome indices were obtained.

Subjective data. Age-specific functional data were obtained from the questionnaire and the referring physician, and a New York Heart Association (NYHA) classification of functional status was derived by consensus of three of the authors (T.L.G., S.B.F., and G.W.). The presence of protein-losing enteropathy or liver disease was confirmed by review of the medical records or by contact with the referring physician.

Objective tests. Records were reviewed for the results of the following assessments obtained during the crosssectional follow-up period: physical examination, chest roentgenogram, and serum liver function tests.

Results of all echocardiograms or cardiac catheterizations after the Fontan operation were recorded (Appendixes $B$ and C). Twelve-lead and ambulatory electrocardiograms and neurologic and psychologic examinations were also undertaken and are the subjects of separate reports. ${ }^{10,13}$ In patients who were not evaluated at our institution, the aforementioned information was obtained from the referring physician.

Statistical analysis. Some outcome measures were not available for all patients. Thus, to determine the extent to which selection bias might have influenced the results, we used the Wilcoxon rank sum test, two-sample $t$ test, or $\chi^{2}$ test, as appropriate, to compare perioperative data for the subset of patients who had the outcome measure with data for those who did not. The primary outcome of interest, NYHA classification of functional status, was assigned from questionnaire data or physician correspondence, or both. This outcome was then collapsed to form two groups, "good" functional status (class I or II) and "poor" functional status (class III or IV). Relationships with perioperative variables were evaluated by means of contingency table methods and logistic regression analysis. When multivariate models were being constructed, a $p$ value of 0.05 was required for retention in the model. Potential interactions among variables included in the model were examined.

\section{Results}

Patient population. Of the 500 patients, 416 $(83.2 \%)$ survived the early postoperative period with their Fontan circulation intact. During the cross-

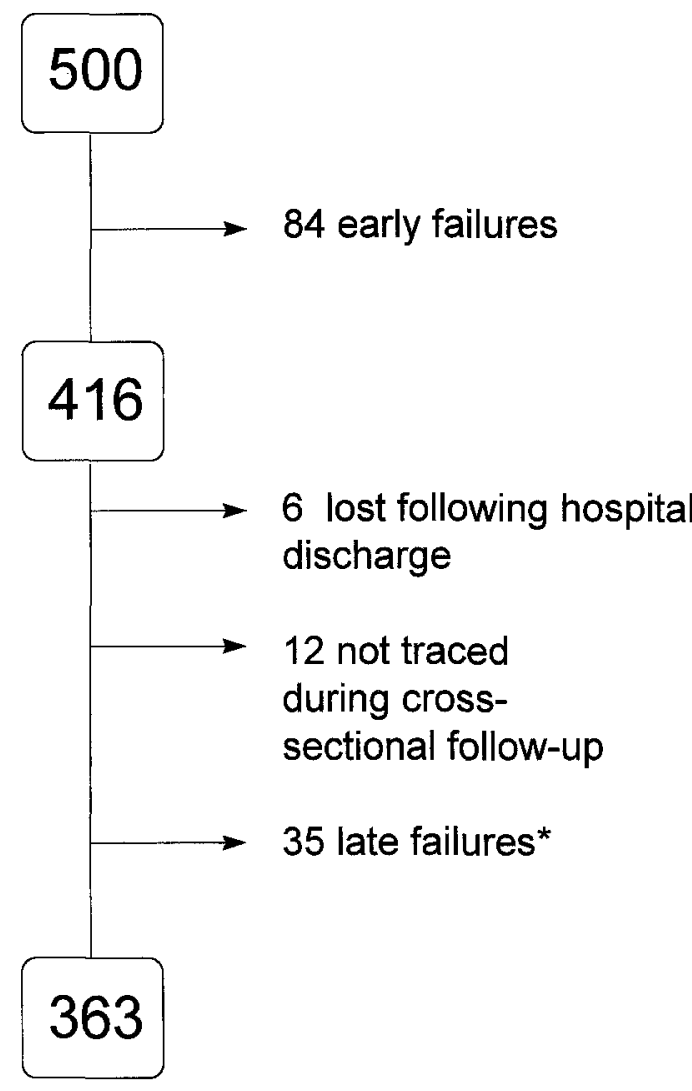

Fig. 1. Outcome in the 500 study patients. *An additional late failure occurred late in the cross-sectional follow-up period. Inasmuch as data collection for this individual had been completed before the failure, this patient has been included in the study group (see text for details).

sectional follow-up period, 398 patients (95.7\%) were accounted for; six were lost to follow-up after hospital discharge and a further 12 patients, known to be alive with a Fontan circulation 1.7 to 9.7 years after the Fontan operation, could not be traced.

A total of 35 late failures occurred (defined as death, takedown of the Fontan circulation to an aortopulmonary or cavopulmonary shunt, or cardiac transplantation) in a total of 2464 patient-years of follow-up (1.42 per 100 patient-years). One additional failure occurred late in the cross-sectional follow-up period; inasmuch as data collection for this individual had been completed before the failure, the information obtained has been included in the following analyses. Hence 363 of 381 potential long-term survivors (95.3\%) with an intact Fontan circulation were identified during the cross-sectional review period (Fig. 1). No significant differences were noted between these 363 patients and the 18 


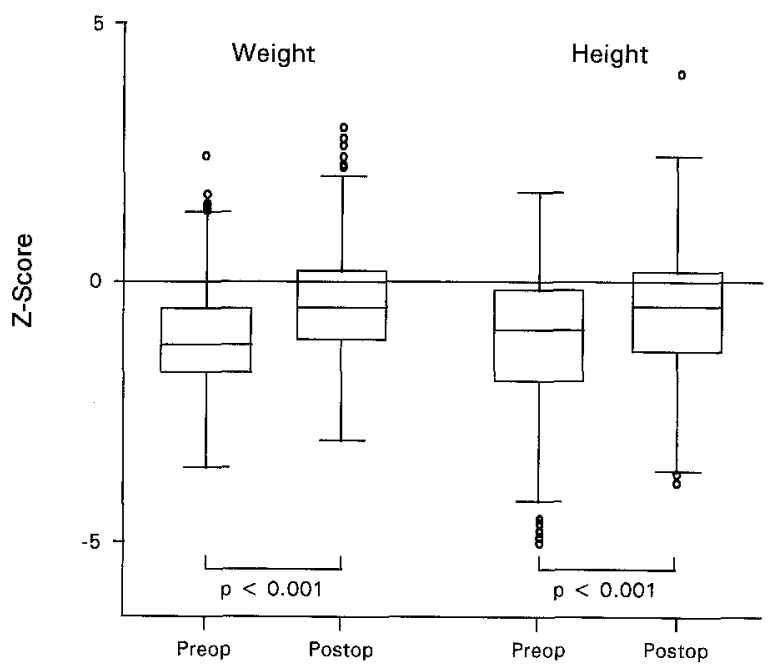

Fig. 2. Box plots of preoperative and postoperative weight and height Z-scores. The central box extends from the 25 th percentile to the 75 th percentile; the center line marks the 50 th percentile (median). The lines projecting from the box encompass the range of the data, excepting outlying values, which are represented by circles.

patients lost to follow-up, except that those lost to follow-up were less likely to have had a baffle fenestration $(1 / 18$ [5.6\%] vs $125 / 363$ [34.4\%], $p=$ $0.01)$.

The median age at operation in the 363 patients identified was 5.0 years (range 0.4 to 31 years). Median follow-up was 5.4 years (range 1.7 to 20 years) and median age at follow-up was 11.1 years (range 3.1 to 42 years). Preoperative diagnoses are detailed in Table I. The Fontan operation involved a conduit between the systemic venous atrium and ventricle or pulmonary artery in 43 patients $(11.8 \%)$, a direct atriopulmonary connection in $120(33.1 \%)$, and a total cavopulmonary anastomosis with an intracardiac lateral tunnel in $200(55.1 \%)$. A residual connection between the systemic venous pathway and pulmonary venous pathway (baffle fenestration) was created in 125 patients (one with a conduit, 15 with a direct anastomosis, and the remainder with a total cavopulmonary anastomosis). ${ }^{14}$ The baffle fenestration was closed with a transcatheter device in 73 patients ( 30 patients early, 43 patients late), closed spontaneously in $29,{ }^{5}$ and remained open in 23 .

Reintervention. Of the 363 patients, $75(20.1 \%)$ underwent 113 late reoperations ( $>30$ days after the modified Fontan operation) and 88 patients $(24.2 \%)$ underwent 128 transcatheter procedures, with an
Table I. Anatomic subtypes

\begin{tabular}{lrr}
\multicolumn{1}{c}{ Diagnostic group } & No. & $\%$ \\
\hline LV-NRGA & 119 & 32.8 \\
LV-TGA & 141 & 38.8 \\
RV/indeterminate V & 43 & 11.8 \\
Heterotaxy syndrome & 26 & 7.2 \\
Hypoplastic left heart syndrome & 14 & 3.9 \\
Other & 20 & 5.5 \\
\hline
\end{tabular}

$L V-N R G A$, Left ventricle with normally related great arteries; $L V-T G A$, left ventricle with transposed or malposed great arteries; RV/indeterminate $V$, right ventricle or ventricle of unknown morphology (excluding hypoplastic left heart syndrome and heterotaxy syndrome).

overall reintervention rate of 10.1 per 100 patientyears (Appendix D). Thirty-four patients (9.4\%) had pacemakers implanted, four before the Fontan operation and 30 after.

Examination characteristics. Height and weight measurements were available in 219 patients. No significant differences were noted in patient- or procedure-related risk factors or in postoperative functional status between those for whom these data were available and those for whom they were not available. Measurements were standardized with respect to age by subtracting the age-specific mean for the normal population and dividing by the standard deviation to create Z-scores. Height was more than two standard deviations below the normal population mean in 30 patients $(13.7 \%)$ and weight in 13 patients $(5.9 \%)$. Overall, the mean height and weight $\mathrm{Z}$-scores were significantly lower than those of a normal population $(-0.6 \pm 1.3$ and $-0.3 \pm 1.2$, respectively; $p<0.001$ for both). However, when compared with preoperative values, a significant increase was observed in both height and weight at follow-up ( $p<0.001$ for both), indicating catch-up growth had occurred after the Fontan operation (Fig. 2). Transcutaneous oximetry was available in 127 patients. The mean oximetry saturation was $93.1 \% \pm 4.1 \%$ and ranged from $80 \%$, in a patient with pulmonary vein stenosis and a baffle fenestration, to $100 \%$. A significant difference was noted between oximetry saturations in patients with an open baffle fenestration $(85.1 \% \pm 2.3 \%)$ and those with no baffle fenestration $(93.6 \% \pm 3.4 \%)$ or with a baffle fenestration that had been closed $(94.7 \% \pm 2.7 \%, p<0.001)$. Other examination findings and chest roentgenographic findings are summarized in Tables II and III.

Questionnaire. A questionnaire was completed by 313 of the 363 patients $(86.2 \%)$. No major differences in patient- or procedure-related risk 
Table II. Additional examination findings

\begin{tabular}{lcc}
$(n=280)$ & & \\
\hline Examination finding & No. & $\%$ \\
\hline Systolic murmur & 175 & 62.5 \\
Systolic thrill & $4^{*}$ & 1.4 \\
Early diastolic murmur & 24 & 8.6 \\
Middiastolic murmur & $4 \dagger$ & 1.4 \\
Ascites & 1 & 0.4 \\
Pitting edema & 7 & 2.5
\end{tabular}

*All four patients with a systolic thrill had systemic ventricular outflow tract obstruction.

tAll four patients with a middiastolic murmur had a systemic venous conduit with a residual resting gradient.

factors were observed between those who returned the questionnaire and those who did not. The median duration of follow-up in these 313 patients was 5.4 years (range 1.7 to 20.2 years), and the median age was 10.3 years (range 2.4 to 41.9 years). Some respondents did not answer each question.

Functional state. Current health was reported as excellent or good by 283 of 310 respondents $(91.3 \%)$, fair by $26(8.4 \%)$, and poor by one $(0.3 \%)$. The questionnaire responses to an age-specific assessment of functional state are summarized in Table IV.

Of the 53 questionnaire respondents aged more than 21 years, $50(94.3 \%)$ have completed high school, 16 (30.2\%) have completed college, 39 $(73.6 \%)$ were employed or were students, and 14 (26.4\%) were not employed. Eight of these 14 patients attributed their lack of employment to their heart condition. Compared with the other 45 patients aged more than 21 years, these eight were in a lower NYHA functional class $(50.0 \%$ class III or IV vs $4.4 \%, p<0.001$ ) and rated their health less favorably ( $62.5 \%$ fair or poor vs $15.6 \%, p=0.003$ ). Health insurance coverage in this adult population was similar to that in the younger age group (89.6\% vs $92.2 \%, p=$ not significant; analysis restricted to U.S. residents).

Medications. A medication history was obtained in 327 patients $(90.1 \%)$. One hundred twenty-four $(37.9 \%)$ were receiving no cardiac medications, and $31(9.5 \%)$ were receiving four or more cardiac medications. Antiarrhythmic medication (other than digoxin) was taken by $36(11.0 \%)$ (Fig. 3).

NYHA functional class. NYHA class could be assigned from questionnaire data or physician correspondence, or both, in 359 patients $(98.9 \%)$ ). No major differences were observed between perioperative variables in the groups with and without a
Table III. Chest roentgenograms $(n=154)$

\begin{tabular}{lrr}
\hline Chest roentogram finding & No. & $\%$ \\
\hline Cardiomegaly & & \\
None & 84 & 54.5 \\
Mild & 37 & 24.0 \\
Moderate & 25 & 16.2 \\
Severe & 2 & 1.3 \\
Not known & 6 & 3.9 \\
Elevated hemidiaphragm & 12 & 7.8 \\
Pleural effusion & 3 & 1.9 \\
\hline
\end{tabular}

known NYHA class, except that patients who had a fenestration were more likely to have had an NYHA class assigned $(p=0.01)$. Of the 359 patients, 327 $(91.1 \%)$ were in class I or II ("good" outcome) whereas $32(8.9 \%)$ were in class III or IV ("poor" outcome) (Table V). Relationships between functional outcome and perioperative variables were evaluated. Results of univariate and multivariate analyses are detailed in Table VI. A multivariate logistic regression model suggested that longer follow-up time (odds ratio 1.3, $p<0.001$ ), a prior atrial septectomy (odds ratio $3.0, p=0.03$ ), and a prior main pulmonary artery-ascending aorta anastomosis or ventricular septal defect enlargement (odds ratio $3.4, p=0.05$ ) were associated with an increased probability of poor NYHA classification. Immediate postoperative variables such as right atrial pressure, duration of hospital stay, and prolonged pleural or pericardial effusions were not independent predictors of functional outcome in the multivariate model. Furthermore, neither the presence or absence of a baffle fenestration at the time of operation, nor its status (open or closed) at the time of follow-up, was associated with functional outcome.

\section{Laboratory investigations}

Synthetic liver function. Serum albumin was below the normal range $(<3.4 \mathrm{gm} / \mathrm{L})$ in four of 92 patients $(4.3 \%)$ for whom data were available: all four had symptomatic protein-losing enteropathy. The prothrombin time was available in 67 patients (excluding those receiving warfarin). It was normal $(<12.5$ seconds) in 28 patients (41.8\%), mildly elevated ( 12.5 to 13.5 seconds) in 36 patients $(53.7 \%$ ), and markedly elevated ( $\geq 14$ seconds) in three patients $(4.5 \%)$, one of whom had protein-losing enteropathy. The international normalized ratio was not systematically recorded.

Enzymatic liver function. Measurements of serum transaminases (aspartate transaminase or alanine 
Table IV. Response to questionnaire-Age-specific functional status

\begin{tabular}{|c|c|c|c|}
\hline Age at follow-up & & No. & $\%$ \\
\hline$<6$ years & Median follow-up duration 2.9 years (range 1.8-5.9 years) & & \\
\hline \multirow[t]{4}{*}{$(n=52)$} & Physical limitation: & & \\
\hline & No limitation & 36 & 69.2 \\
\hline & Slight limitation (stops playing earlier than peers) & 13 & 25.0 \\
\hline & Severe limitation (unable to partake in "usual" activities) & 3 & 5.8 \\
\hline $6-17$ years & Median follow-up duration 5.4 years (range $1.7-15.3$ years) & & \\
\hline \multirow[t]{5}{*}{$(\mathrm{A}: n=187)$} & Physical limitation: & & \\
\hline & No limitation & 65 & 34.8 \\
\hline & Slight limitation & 93 & 49.7 \\
\hline & Significant limitation & 27 & 14.4 \\
\hline & Severe limitation & 2 & 1.1 \\
\hline \multirow[t]{5}{*}{$(\mathrm{B}: n=184)$} & Maximal amount of activity: & & \\
\hline & Takes part in gym class, keeps up with peers & 82 & 44.6 \\
\hline & Takes part in gym class, does not keep up & 78 & 42.4 \\
\hline & Cannot take part in gym class, tires walking one block & 18 & 9.8 \\
\hline & Unable to judge & 6 & 3.3 \\
\hline$\geq 18$ years & Median follow-up duration 9.9 years (range $2.2-20.2$ years) & & \\
\hline \multirow[t]{5}{*}{$(A: n=69)$} & Physical limitation: & & \\
\hline & No limitation & 13 & 18.8 \\
\hline & Slight limitation & 43 & 62.3 \\
\hline & Significant limitation & 11 & 15.9 \\
\hline & Unable to perform daily living tasks without discomfort & 2 & 2.9 \\
\hline \multirow[t]{7}{*}{$(\mathrm{B}: n=70)$} & Maximal amount of activity: & & \\
\hline & Participate in strenuous activity & 15 & 21.4 \\
\hline & Climb three flights of stairs & 20 & 28.6 \\
\hline & Perform heavy housework & 8 & 11.4 \\
\hline & Participate in light sports & 12 & 17.1 \\
\hline & Climb one flight of stairs & 10 & 14.3 \\
\hline & Perform light housework & 5 & 7.1 \\
\hline
\end{tabular}

Note: Not all patients responded to all questions.

transaminase) were available in 97 patients and were within normal limits in four $(4.1 \%)$, mildly elevated (less than twice the upper limit of normal) in $86(88.7 \%)$, moderately elevated (two to three times the upper limit of normal) in five (5.2\%), and severely elevated (more than three times the upper limit of normal) in two patients $(2.1 \%)$. No patient is known to have cirrhosis, but one individual with serologic evidence of previous hepatitis $\mathrm{C}$ infection has chronic active hepatitis.

Protein-losing enteropathy. Protein-losing enteropathy, defined as persistent hypoalbuminemia $(<3.0 \mathrm{mg} / \mathrm{dl})$ in the absence of liver or renal disease, with accompanying clinical features including abdominal pain, diarrhea, edema, and ascites, was present in nine of the 363 patients $(2.5 \%)$ traced during the cross-sectional follow-up period. An additional two patients whose Fontan circulations failed before the cross-sectional follow-up period were known to have protein-losing enteropathy. Hence protein-losing enteropathy developed in 11 of the 416 early survivors $(2.6 \%)$ with an intact
Fontan circulation, a rate of 0.45 cases per 100 patient-years.

\section{Discussion}

This study details the functional status of a large number of patients who underwent the Fontan operation over a period that encompassed many changes in preoperative management and operative technique. The majority of patients (more than $90 \%$ ) perceived their state of health to be good or excellent and were able to partake in most of the activities of daily living. Most adults were either employed or continuing tertiary education, a finding similar to that reported by Mair, Puga, and Danielson. ${ }^{15}$ Nevertheless, cardiac medication use was common, and reintervention was frequent. Furthermore, a small group of patients were more severely limited and, disturbingly, the incidence of limitation appeared to be related to length of follow-up. Because duration of follow-up in this cohort is closely related to age at follow-up, date of operation, age at operation, and type of operation, it is not 


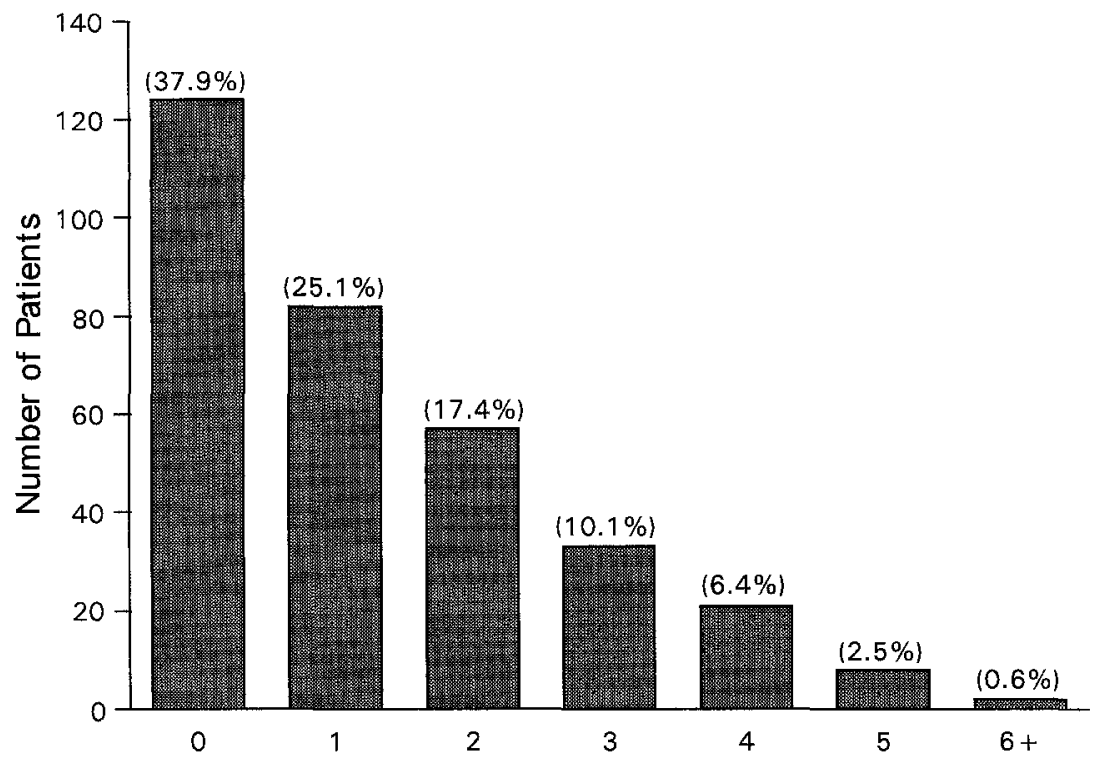

A

Number of Cardiac Medications

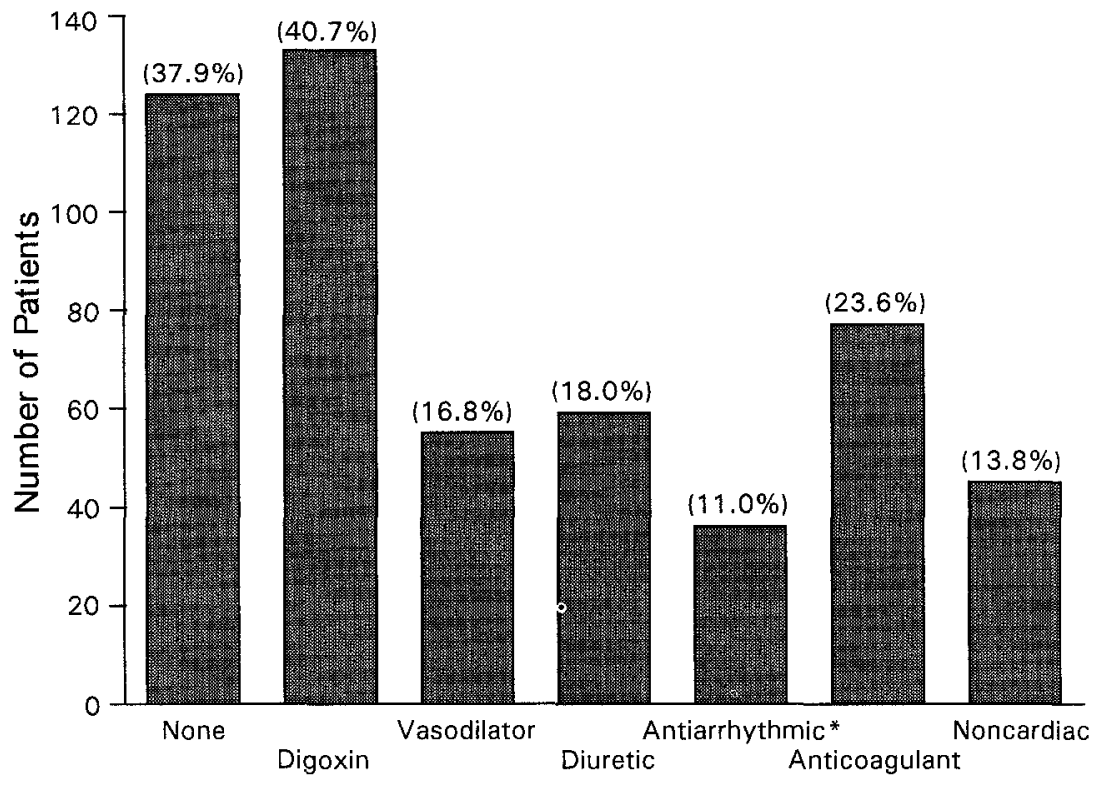

B

Type of Medication

Fig. 3. A, Number of medications per patient. B, Type of medications (many patients were receiving more than one type of medication). *Antiarrhythmic medication other than digoxin.

possible to be certain as to the cause of the poorer functional state of patients followed up for longer periods. In addition, the perception of limitation and expectations alter with age; limitations are less apparent to the parents and family of young children than they are to adolescents and adults. Nir and coworkers ${ }^{16}$ found no deterioration in serial exercise tests in a small group of patients after the Fontan operation, suggesting that changing expectations may be an important factor.

Procedural variables including a history of prior atrial septectomy, main pulmonary artery-ascending aorta anastomosis, or ventricular septal defect enlargement were also associated with a poor functional state. These procedures are common in patients with left-sided atrioventricular valve atresia or 
Table V. NYHA functional class at follow-up $(n=359)$

\begin{tabular}{crc}
\hline NYHA class & No. & $\%$ \\
\hline I & 190 & 52.9 \\
II & 137 & 38.2 \\
III & 32 & 8.9 \\
IV & 0 & 0.0 \\
\hline
\end{tabular}

stenosis, left ventricular hypoplasia, and obstruction of the systemic outflow tract. We have also found these anatomic subgroups to be associated with a higher risk of early and late failure of the Fontan circulation. $^{5}$ Reasons for the poorer outcome in these subgroups are speculative and probably multiple. Ventricular hypertrophy exacerbated by outflow tract obstruction may impair diastolic function and thus increase central venous pressure. ${ }^{17}$ Only three patients in this series had ventricular septal defect enlargement; thus it is unlikely that ventricular dysfunction resulting from myocardial resection is a contributing cause. However, many did have hypoplastic left heart syndrome, an anatomic subtype particularly at risk for ventricular dysfunction as a result of ventricular morphology, coronary artery anomalies, extensive palliative procedures in early infancy, or residual arch obstruction.

Neither the presence nor absence of a baffle fenestration was related to functional outcome. Although numbers are small-only 23 patients had an open fenestration at follow-up-these findings suggest that mild arterial desaturation is well tolerated. Fenestration closure frequently results in a fall in resting cardiac output and an increase in systemic venous pressure. ${ }^{18}$ Furthermore, it is possible that the ability to increase cardiac output with exercise is enhanced when a patent fenestration is in place. A study of cardiorespiratory exercise capacity before and after fenestration closure would clarify this issue.

Driscoll and colleagues ${ }^{7}$ have identified heterotaxy as a risk factor for death and for a poor functional outcome in survivors. Although heterotaxy syndrome was not a risk factor for poor functional outcome in the current series, $\mathrm{we}^{5}$ have found it to be a predictor of late failure of the Fontan circulation; many patients with heterotaxy syndrome had Fontan failure before the cross-sectional review and therefore could not be included in an analysis of late functional outcome.

Atrial arrhythmias, especially sinus node dysfunction and atrial flutter, are an important cause of morbidity after the Fontan operation. A significant minority of patients in the current series were receiving antiarrhythmic medication or had undergone pacemaker implantation. Using the same patient cohort, we $\mathrm{e}^{10}$ have previously demonstrated that atrial flutter was less likely to occur in patients in NYHA class I (10\%) than in those with class II or class III symptoms ( $21 \%$ and $26 \%$, respectively, $p=$ 0.02 ). In addition, the atrial flutter became more prevalent with increasing duration of follow-up; the probability of freedom from atrial flutter was $94.6 \%$ at 2 years, $89.7 \%$ at 5 years, and $67.7 \%$ at 10 years. Atrial arrhythmias may well have contributed to the association between poor functional outcome and duration of follow-up in the current series.

Although height and weight were lower than those of the normal population, the group as a whole exhibited "catch-up" growth after the Fontan operation. This suggests that many patients had a more favorable hemodynamic state after the operation than before; chronic preoperative cyanosis and congestive heart failure may have a greater impact on growth than the elevated central venous pressure and low-normal cardiac output after the Fontan operation. Neurologic, psychologic, and developmental abnormalities are another important cause of morbidity in this patient group. A detailed investigation in a subgroup of this cohort is the subject of a separate report. ${ }^{19}$

Laboratory investigations. Minor abnormalities in serum liver function tests were common. Others have reported a small but important incidence of cirrhosis after the Fontan operation. ${ }^{7}$ Our study population included no patients with cirrhosis, but a number, who have not had definitive investigations, had at least moderately elevated transaminase levels. In addition to hepatic congestion, transfusionrelated hepatitis, particularly hepatitis $\mathrm{C}$, should be considered as a cause of elevated transaminase levels. Abnormal coagulation factors, particularly the procoagulation factor protein $\mathrm{C}$, have been reported after the Fontan operation. ${ }^{20}$ To our knowledge, a high prevalence of abnormal prothrombin times has not been reported. This finding may be related to hepatic dysfunction resulting from chronic congestion and carries important clinical implications; care should be taken when administering medication that requires hepatic metabolism and especially when titrating warfarin for anticoagulation.

Limitations. This cross-sectional review documents the functional state of a large number of 
Table VI. Perioperative variables associated with a poor functional outcome $(n=359)$

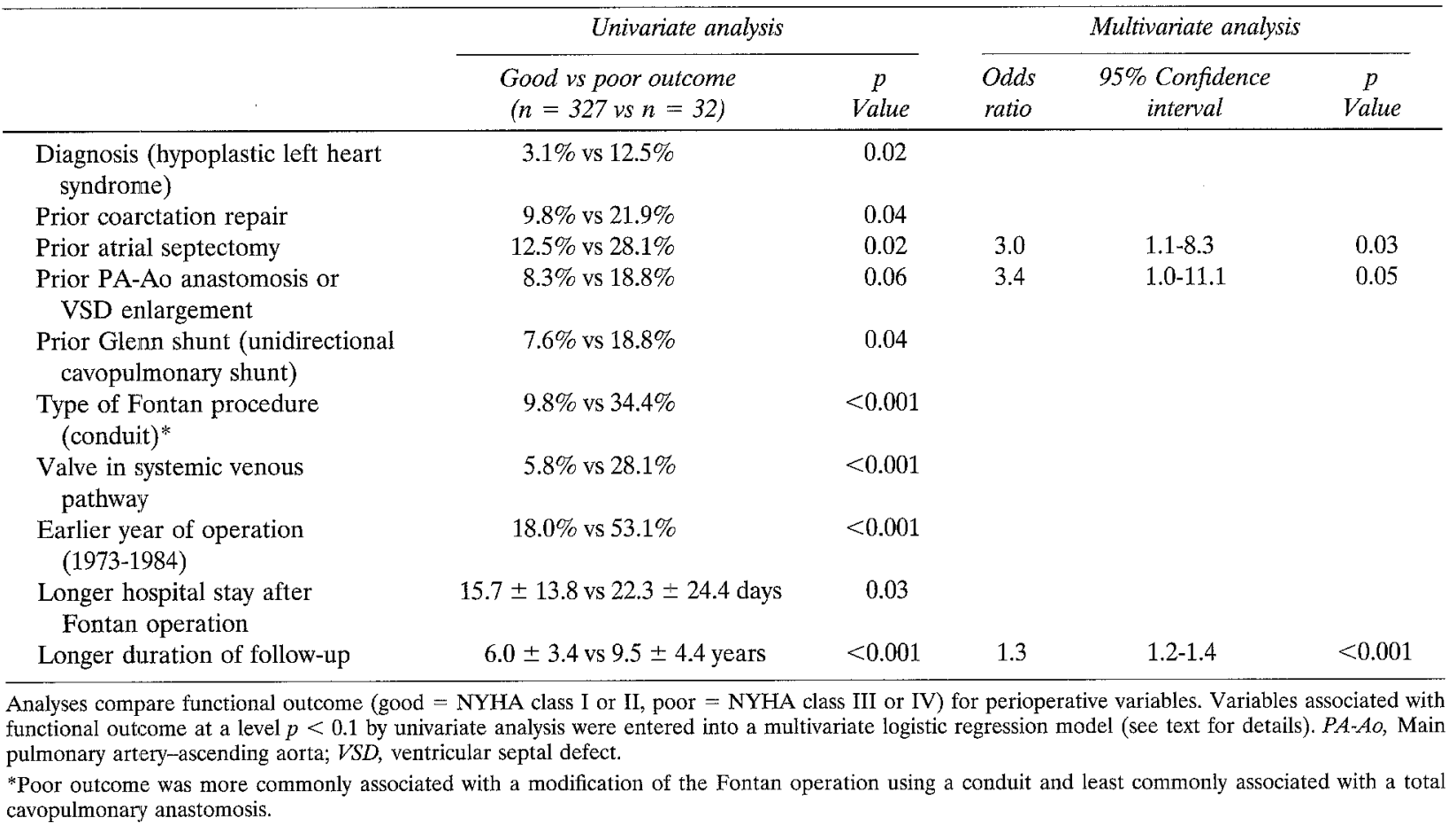

patients who underwent the Fontan operation between 1973 and 1991 and survived with an intact circulation. Those in whom the Fontan repair failed before the cross-sectional review are not included in the current analysis but are the subject of a separate report. ${ }^{5}$ It is possible that outcomes in this study may not reflect the expected long-term results in those operated on more recently at our institution. Patients now tend to be younger at the time of the Fontan operation and are more likely to have an intermediate bidirectional cavopulmonary shunt. They are therefore less likely to be exposed to long-standing ventricular volume overload. Perhaps most important, the duration of "late" postoperative follow-up remains relatively short. Information gathered over the coming decades will further delineate the progress of this challenging group.

A large number of variables were analyzed with respect to functional outcome. However, operations were performed over several decades, and it was not possible to gather sufficient data relative to factors such as preoperative ventricular hypertrophy or pulmonary artery size that may well affect late outcome. ${ }^{17,21}$ In addition, catheterization and echocardiographic data available at the time of the cross-sectional review were unsuitable for analysis in that they had frequently been collected because of a specific clinical concern. It was therefore not possible to relate factors such as postoperative hemodynamics, ventricular function, or atrioventricular valve regurgitation to functional outcome.

\section{Conclusions}

At a mean follow-up of 5.4 years after the Fontan operation, more than $90 \%$ of patients are satisfied with their overall health and quality of life. Catch-up growth occurs after the Fontan operation, but height and weight are less than in the normal population. Furthermore, late reintervention, medication use, and liver function abnormalities are prevalent. Functional state may deteriorate with increasing duration of follow-up, but the cause of this phenomenon is not clear.

We thank Drs. Aldo R. Castaneda, Richard A. Jonas, William I. Norwood, and Frank L. Hanley, who operated on many of these patients, and Dr. James E. Lock for his critical review of the manuscript. We also thank the referring cardiologists for their assistance with patient contact and their provision of follow-up information. Finally, we thank Jocelyn Wise, Andrea Fishberger, and Mary Dwyer for their assistance with patient follow-up and data management. 


\section{REFERENCES}

1. Mair DD, Hagler DJ, Julsrud PR, Puga FJ, Schaff HV, Danielson GK. Early and late results of the modified Fontan procedure for double-inlet left ventricle: the Mayo Clinic experience. J Am Coll Cardiol 1991;18:1727-32.

2. Mair DD, Hagler DJ, Puga FJ, Schaff HV, Danielson GK. Fontan operation in 176 patients with tricuspid atresia: results and a proposed new index for patient selection. Circulation 1990;82(Suppl):1V164-9.

3. Mayer JE Jr, Helgason H, Jonas RA, et al. Extending the limits for modified Fontan procedures. J Thorac Cardiovasc Surg 1986;92:1021-8.

4. Mayer JE Jr, Bridges ND, Lock JE, Hanley FL, Jonas RA, Castaneda AR. Factors associated with marked reduction in mortality for Fontan operations in patients with single ventricle. J Thorac Cardiovasc Surg 1992;103:444-51.

5. Gentles TL, Mayer JE Jr, Gauvreau K, et al. Fontan operation in five hundred consecutive patients: factors influencing early and late outcome. J Thorac Cardiovasc Surg. In press.

6. Fontan F, Kirklin JW, Fernandez G, et al. Outcome after a "perfect" Fontan operation. Circulation 1990;81:1520-36.

7. Driscoll DJ, Offord KP, Feldt RH, Schaff HV, Puga FJ, Danielson GK. Five- to fifteen-year follow-up after the Fontan operation. Circulation 1992;85:469-96.

8. Driscoll DJ, Danielson GK, Puga FJ, Schaff HV, Heise CT, Staats BA. Exercise tolerance and cardiorespiratory response to exercise after the Fontan operation for tricuspid atresia or functional single ventricle. J Am Coll Cardiol 1986;7:1087-94.

9. Weber HS, Hellenbrand WE, Kleinman CS, Perlmutter RA, Rosenfeld LE. Predictors of rhythm disturbances and subsequent morbidity after the Fontan operation. Am J Cardiol 1989;64:762-7.

10. Fishberger SB, Wernovsky G, Gentles TL, Gauvreau K, Burnett J, Mayer JE Jr, Walsh EP. Factors influencing the development of atrial flutter after the Fontan operation. J Thorac Cardiovase Surg 1997;113:80-6.

11. du Plessis AJ, Chang AC, Wessel DL, et al. Cerebrovascular accidents following the Fontan operation. Pediatr Neurol 1995;12:230-6.

12. Hess J, Kruizinga K, Bijleveld CMA, Hardjowijono R, Eygelaar A. Protein-losing enteropathy after Fontan operation. J Thorac Cardiovasc Surg 1984;88:606-9.

13. Fishberger SB, Wernovsky G, Gentles TL, et al. Long-term outcome in Fontan patients with pacemakers. Am J Cardiol 1996; 77:887-9.

14. Jonas RA, Castaneda AR. Modified Fontan procedure: atrial baffle and systemic venous to pulmonary artery anastomotic techniques. J Card Surg 1988;3:91-6.

15. Mair DD, Puga FJ, Danielson GK. Late functional status of survivors of the Fontan procedure performed during the 1970s. Circulation 1992;86(Suppl):II106-9.

16. Nir A, Driscoll DJ, Mottram CD, et al. Cardiorespiratory response to exercise after the Fontan operation: a serial study: J Am Coll Cardiol 1993;22:216-20.

17. Kirklin JK, Blackstone EH, Kirklin JW, Pacifico AD, Bargeron LM Jr. The Fontan operation: ventricular hypertrophy, age, and date of operation as risk factors. $\mathrm{J}$ Thorac Cardiovasc Surg 1986;92:1049-64.

18. Bridges ND, Lock JE, Mayer JE Jr, Burnett J, Castaneda AR. Cardiac catheterization and test occlusion of the interatrial communication after the fenestrated Fontan operation. J Am Coll Cardiol 1995;25:1712-7.

19. Wernovsky G, Stiles KM, Gauvreau K, du Plessis AJ, Walsh AZ, Gentles TL, et al. Cognitive development following the Fontan operation [abstract]. Circulation 1995; 92(Suppl):I121.

20. Cromme-Dijkhuis AH, Hess J, Hahlen K, et al. Specific sequelae after the Fontan operation at mid- and long-term follow-up. J Thorac Cardiovasc Surg 1993;106:1126-32.

21. Fontan F, Fernandez G, Costa F, Naftel DC, Tritto F, Blackstone $\mathrm{EH}$, et al. The size of the pulmonary arteries and the results of the Fontan operation. J Thorac Cardiovasc Surg 1989;98:711-9. 


\section{Appendix A. Perioperative variables}

Patient-related

Demographics

Diagnosis

Atrioventricular valve anatomy

Systemic ventricular morphology

Anomalous pulmonary venous drainage

Anomalous systemic venous drainage

Atrioventricular valve regurgitation

Pulmonary artery distortion

Previous procedures

Preoperative hemodynamics

Procedure-related

Type of atriopulmonary connection

Baffle fenestration

Coronary sinus position

Origin of the atriopulmonary connection

Distal connection points

Valve in atriopulmonary connection

Valve anywhere on right side

Additional procedures

Myocardial preservation technique

Cardiopulmonary bypass time

Aortic crossclamp time

Postoperative-immediate

Systemic atrioventricular valve

Systemic ventricle

Systemic atrioventricular valve/baffle relationship

Postoperative pressures on day of surgery

Postoperative-other

Prolonged effusions (drainage $\geq 14$ days)

Duration of hospital stay

Reoperations

Baffle fenestration
Age at operation

Year of operation

Sex

Left ventricle with normally related great arteries

Left ventricle with transposed great arteries

Right ventricle and ventricle with unknown morphology

Hypoplastic left heart syndrome

Heterotaxy syndrome

Other

Yes, no

Yes, no

None, mild, moderate, severe

Yes, no

Aortopulmonary shunt

Atrial septectomy

Pulmonary artery band

PA-Ao anastomosis or VSD enlargement

Coarctation repair

Unidirectional cavopulmonary shunt (Glenn)

Bidirectional cavopulmonary shunt (bidirectional

Glenn)

Pulmonary artery reconstruction

Pacemaker

Ao saturation, hemoglobin

LAp, RAp, Aop, PAp

Qp, Qs, Qp/Qs, Qp + Qs, PVR

Ventricular work $((\mathrm{Qp}+\mathrm{Qs}) \times$ Aop)

Total resistance to pulmonary blood flow

$$
([\mathrm{LAp} /(\mathrm{Qp}+\mathrm{Qs})]+\mathrm{PVR})
$$

Conduit

Direct

Total cavopulmonary anastomosis with lateral tunnel

Yes, no

Left, right

Yes, no

Yes, no

Left, right, both, indeterminant

Systemic venous atrium and pulmonary venous atrium

Yes, no

None, minor, major

Never, open, closed

$P A-A o$, Pulmonary artery-ascending aorta; $V S D$, ventricular septal defect; $L A p$, mean left atrial pressure; $R A p$, mean right atrial pressure; $A o p$, mean aortic pressure; $P A p$, mean pulmonary artery pressure; $Q p$, indexed pulmonary blood flow; $Q s$, indexed systemic blood flow; $P V R$, indexed pulmonary vascular resistance (see text for details). 
Appendix B. Echocardiographic findings $(n=281)(5.3 \pm 3.8$ years after the Fontan operation)

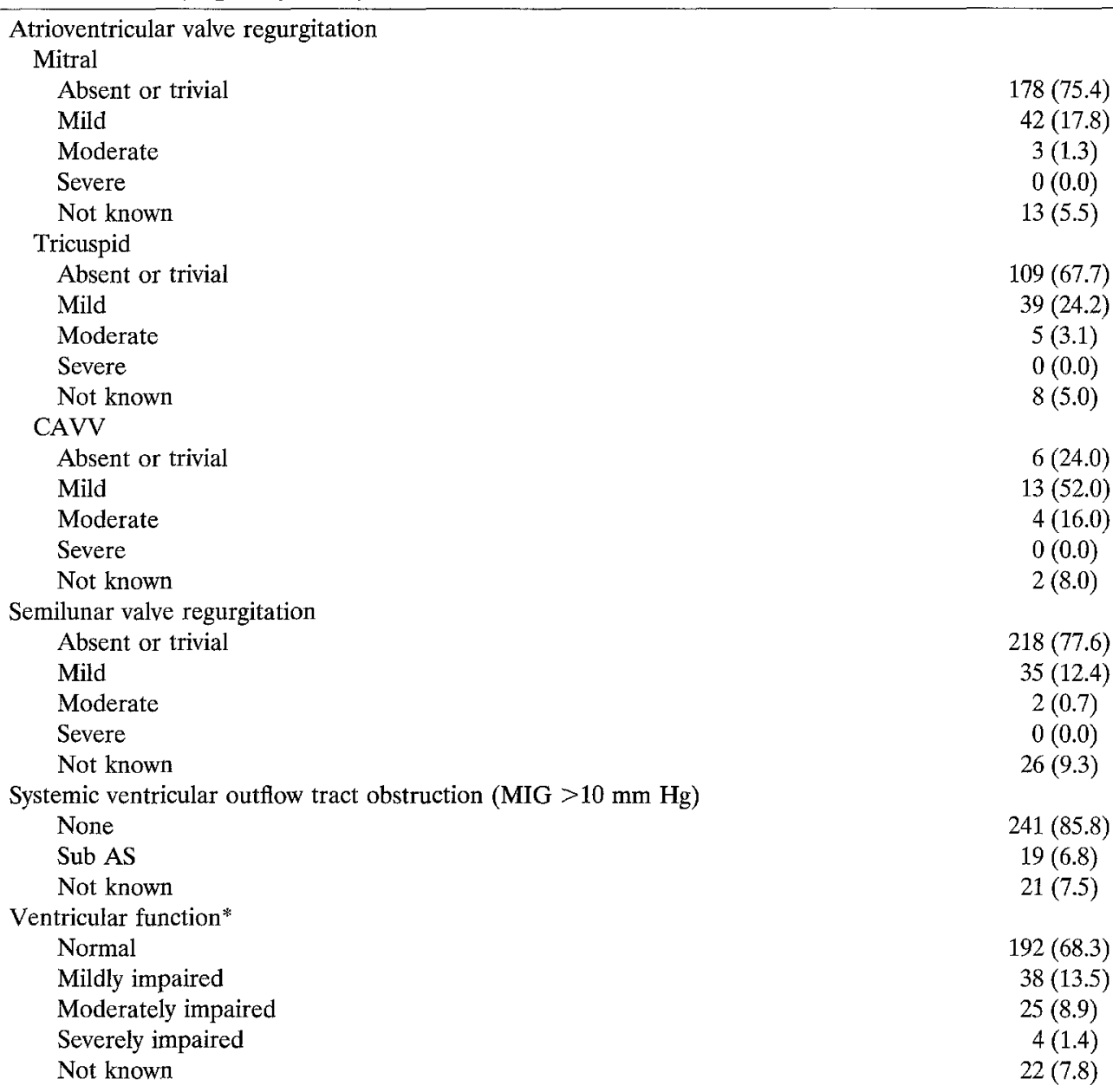

$C A V V$, Common atrioventricular valve; $M I G$, Doppler-derived maximal instantaneous gradient; Sub $A S$, subaortic stenosis. * Subjective assessment of ventricular function.

Appendix C. Postoperative catheterization hemodynamics $(n=177)(3.5 \pm 3.8$ years after the Fontan operation)

\begin{tabular}{lccc}
\multicolumn{1}{c}{ Variable } & No. & Mean $\pm S D$ & Range \\
\hline Systemic venous atrial pressure $(\mathrm{mm} \mathrm{Hg}) *$ & 174 & $12.3 \pm 3.6$ & $5-24$ \\
Pulmonary artery pressure $(\mathrm{mm} \mathrm{Hg})$ & 173 & $11.7 \pm 3.4$ & $4-22$ \\
Pulmonary artery wedge pressure $(\mathrm{mm} \mathrm{Hg})$ & 143 & $7.2 \pm 3.2$ & $1-18$ \\
Aortic saturation $(\%)$ & 172 & $92.8 \pm 4.5$ & $76-100$ \\
Cardiac index $\left(\mathrm{L} / \mathrm{min} / \mathrm{m}^{2}\right)$ & 149 & $2.5 \pm 0.8$ & $1.1-4.8$ \\
Pulmonary vascular resistance $\left(\mathrm{wu} \cdot \mathrm{m}^{2}\right)$ & 121 & $2.3 \pm 1.3$ & $0.7-9.0$ \\
Systemic vascular resistance $\left(\mathrm{wu} \cdot \mathrm{m}^{2}\right)$ & 131 & $29.6 \pm 10.8$ & $12-74$ \\
\hline
\end{tabular}

SD, Standard deviation.

*There was a mean gradient $>2 \mathrm{~mm} \mathrm{Hg}$ between the systemic venous "atrium" and the pulmonary arteries in $36 \%$ of patients with a systemic venous conduit (many of whom were catheterized because of suspected conduit obstruction), in 6\% of patients with a direct right atrium-pulmonary artery anastomosis, and in no patient with a total cavopulmonary anastomosis. 


\section{Appendix D. Late reintervention}

\section{Late reoperation (113 procedures in 75 patients)}

Pacemaker insertion/replacement

Conduit revision/replacement

Relief of subaortic obstruction

Closure of residual atrial right-to-left shunt

Pericardiotomy

Revision of right atrioventricular valve patch

Conversion to total cavopulmonary anastomosis

Baffle revision or cavopulmonary anastomosis for systemic venous obstruction

Atrioventricular valve replacement

Baffle revision for pulmonary venous obstruction

Closure of residual left-to-right shunt

Interventional cardiac catheterization (128 procedures in 88 patients)

Clamshell closure of fenestration

Coil embolization of aortopulmonary collaterals

Device or coil occlusion of residual defect in atrial baffle

Stent placement in systemic venous conduit

Branch pulmonary arterioplasty

Radiofrequency ablation

Stent placement for systemic ventricular outflow tract obstruction

Dilation of stenosed conduit or cavopulmonary anastomosis

Device closure of residual ventricular-cavopulmonary communication 